\title{
BMJ Global Health How local context influences access to neuropsychological rehabilitation after acquired brain injury in South Africa
}

\author{
Noorjehan Joosub
}

To cite: Joosub N. How local context influences access to neuropsychological rehabilitation after acquired brain injury in South Africa. BMJ Global Health 2019;4:e001353. doi:10.1136/ bmjgh-2018-001353

Handling editor Seye Abimbola

- Additional material is published online only. To view please visit the journal online (http://dx.doi.org/10. 1136bmjgh-2018-001353).

Received 6 December 2018 Revised 8 March 2019 Accepted 19 April 2019

\section{Check for updates}

C) Author(s) (or their employer(s)) 2019. Re-use permitted under CC BY-NC. No commercial re-use. See rights and permissions. Published by BMJ.

Department of Psychology, University of Johannesburg, Johannesburg, South Africa

Correspondence to Noorjehan Joosub; noorjehanjoosub@gmail.com

\section{ABSTRACT}

The numbers of acquired brain injury (ABI) survivors in South Africa are increasing; however, facilities to provide neuropsychological rehabilitation are limited due to a lack of healthcare resources. The updated International Classification of Health, Functioning, and Disability (ICF) from the WHO emphasises how the context of an impairment influences the patient's activity limitations and participation restrictions. This analysis examined South African contextual influences on the accessibility, quality and efficiency of neuropsychological rehabilitation interventions after $A B I$ in South Africa. Three main contextual influences were identified, namely, socioeconomic disparities, sociocultural influences and discharge to underprepared communities. Systems thinking and inclusive models of healthcare are needed in low-income and middle-income countries, such as South Africa, where resource constraints necessitate creative and ecological forms of rehabilitation interventions after $\mathrm{ABI}$. Contextual influences are vital to consider when designing neuropsychological rehabilitation interventions in order to improve the accessibility and relevance of these interventions and to ensure the effective utilisation of scarce healthcare resources.

\section{INTRODUCTION}

Acquired brain injury (ABI) is 'a diverse condition involving occurrence of events that affect brain functioning such as closed, open, and blast traumatic brain injury (TBI), brain infections, tumors and radiation, hypoxia, and stroke'. ${ }^{\prime}$ Neuropsychological rehabilitation (NR) focuses on assisting brain injury survivors who have cognitive, emotional or behavioural deficits to live up to their potential in all facets of their everyday functioning. ${ }^{2}$ Common deficits after ABI include cognitive impairments, behavioural changes, emotion dysregulation and executive dysfunction. ${ }^{3}$ The WHO's ${ }^{4}$ International Classification of Functioning, Disability, and Health (ICF) categorises consequences after an injury according to bodily functions, functional activities and social participation, all of which are commonly affected after ABI. ${ }^{5}$

\section{Summary box}

Neuropsychological rehabilitation improves quality of life after acquired brain injury.

- There are contextual influences that hamper the accessibility of neuropsychological rehabilitation to those who need it in South Africa.

- These influences include socioeconomic disparities, sociocultural influences and the discharge of patients to underprepared communities

- Contextual influences are an important factor to consider when designing neuropsychological rehabilitation interventions after acquired brain injury.

- The design of neuropsychological rehabilitation interventions requires systems thinking that takes contextual factors into account.

The NR programmes in developed countries have limited patient numbers and interdisciplinary teams and are prohibitively expensive. ${ }^{6}$ The economic costs of an ABI extend throughout the person's lifetime due to the chronic nature of the difficulties. However, there is overwhelming evidence that NR assists with improvements to patients' and their families' lives after ABI. This disconnect between the need for NR and the lack of healthcare resources allocated to it leads to a lack of accessibility for patients with $\mathrm{ABI}$, particularly in low-income and middleincome countries (LMICs).

In LMICs like South Africa, large populations, inaccessible rural areas, few professionals and a lack of awareness of the long-term consequences of ABI lead to the provision of NR services to be scarcely adequate for the need. ${ }^{8}$ Therefore, there is a need for innovation and more effective service-delivery models for NR in LMICs.

The research question for this analysis was: what are the South African contextual factors that influence the accessibility of NR after ABI? The research design followed an exploratory, descriptive approach based on programme theory. The steps included 
determining the question(s) that need to be answered, investigating the literature for possible answers to the questions and evaluating the evidence in the literature for its validity, relevance and applicability to the South African context (online supplementary appendix A has more information).

\section{SOCIOECONOMIC DISPARITIES}

There is a huge divide in the healthcare services available to the wealthy minority in contrast to the lack of accessibility of services for the poor in South Africa. ${ }^{9}$ Therefore, those from underprivileged communities suffer from a lack of accessibility to mental health services in general and NR in particular. A lack of safe public transport, the lack of protection for pedestrians, a large number of children forced to walk long distances to school, the lack of provision of sidewalks and inadequate law enforcement for traffic violations contribute to difficulties in preventing debilitating head injuries, especially in vulnerable groups. ${ }^{10}$

Material exploitation and class inequality are related to the oppressive political history of South Africa that left an enduring legacy of fragmented healthcare systems and skewed geopolitical priorities. ${ }^{11}$ People from lower socioeconomic groups and with adverse premorbid life circumstances have a higher chance of sustaining an ABI. ${ }^{12}$ The sequelae of ABI are more severe and debilitating than that in developed countries due to a lack of adequate acute and postacute healthcare services and the poor quality of services for those with disabilities. ${ }^{13}$ NR approaches cannot be successful without macrosystemic changes, such as access to housing, and antidiscrimination legislation that promotes the employment of those with ABI and other disabilities. ${ }^{12}$ Therefore, the lack of access to basic services has a concomitant effect on the poorer outcomes for those who have ABI from poorer socioeconomic backgrounds.

There is a great need for psychological services in South Africa to advocate for psychoeducational and support services that serve a wider patient base, as opposed to the current one-on-one psychotherapy model. ${ }^{9}$ Groupbased community outreach initiatives could improve the accessibility of NR for those who need it most. Based on the need for systems thinking in LMICs, it is necessary for professionals and psychologists in training in major urban areas to volunteer their services for a time in outlying areas and to train support workers in these areas to ensure the accessibility of mental health services in South Africa. ${ }^{9}$

\section{SOCIOCULTURAL INFLUENCES}

Due to the racial segregation inherent in the apartheid system in South Africa, African traditional beliefs were excluded from the healthcare system. ${ }^{14}$ Indigenous healing and beliefs have been overshadowed by mainstream medical influences but need to be viewed as an integral resource in assisting the process of NR. ${ }^{9}$ African cultural understandings of the aetiology of ABI include spirituality, thwasa (calling to be a traditional healer), ancestral spirits, God's anger and Satan. Based on these varying understandings of the causes of the injury, people seek treatment from God, traditional healers, religious clerics and spiritual forces, all of which are seen to sometimes be more accessible than biomedical treatments and primary healthcare services, which are, at most times, lacking. ${ }^{15}$ Healing ceremonies, collectivist practices and Ubuntu principles should be seen as resources that assist the patient and their families in South Africa.

In a South African study ${ }^{16}$ on ABI patients and caregivers, family members expressed denial regarding the permanence of the ABI and its sequelae. They garnered the hope that one day the patient would return to their former self. This could be related to the African cultural view that symptoms are due to witchcraft or the ancestors, forces that could receive mediation and would allow symptoms to subside. ${ }^{15}$ The lack of accommodation by Western biomedical systems to these beliefs leads to a lack of respect and mistrust between healthcare practitioners and those with ABI. This discourages the constructive collaboration of the two health belief systems for the benefit of the patient.

The concept of Ubuntu, which emphasises interconnectedness, interdependence and the importance of communal relationships, ${ }^{17}$ may assist spontaneous recovery after an $\mathrm{ABI}$ when communities promote the reintegration of patients into their societies. The challenge with this spirit of caring and compassion is there may be a tendency to overprotect the patient. Religion is a coping tool, giving caregivers the strength to believe that the ABI is God's test and also as a means of gaining material assistance from other congregants. Psychologists should be involved in dismantling stigmatised discourses through health promotion, advocacy and illness prevention services.

\section{DISCHARGE OF PATIENTS TO UNDERPREPARED COMMUNITIES}

Due to the lack of quality healthcare accessible to the majority of the South African population, ${ }^{18}$ many ABI survivors are discharged to family and community members,${ }^{19}$ who are often not ready to face the changes that occur after an ABI. The home setting of the patient needs to be taken into account in NR planning, using natural supports and cultural strengths. ${ }^{20}$ Community members, in the spirit of Ubuntu, are open to caring for the ill $^{17}$; however, there is an increasing culture of individualism in younger generations, ${ }^{21}$ which may lead to less support available to patients in their communities.

Social advocacy is essential for ensuring that there is reintegration of the individual with $\mathrm{ABI}$ into society and that the society adapts to the individual. Recent emphases on systems thinking in health systems have allowed for a focus on improving capacity and agency within local, existing systems and resources. ${ }^{22}$ The social and behavioural determinants of health have to be 
understood within the patient's context ${ }^{9}$ and community rehabilitation facilitators (CRFs) from within the same community as the patient are often better equipped to investigate and examine these phenomena. Healthcare practitioners in these contexts need to advocate for social mobilisation and community agency. ${ }^{23}$ However, traditional norms of professional boundaries and autonomy may threaten interprofessional collaboration and the devolution of specialist skills to CRFs. ${ }^{24}$

Caregivers of ABI patients have reported difficulties accessing information about the injury, ${ }^{19}$ its potential consequences and coping strategies for cognitive impairments, personality and behavioural disturbances. Survivors of ABI struggle with social isolation, a lack of meaningful activity, physical symptoms, depression and anxiety. Support groups are valuable resources for the patient and the family to assist with acceptance, psychoeducation and communal support.

Many households in South Africa, particularly in outlying areas, do not have access to running water, electricity or basic sanitation services. ${ }^{25}$ Therefore, family members and communities are underprepared and have a lack of adequate support to deal with the patient's need for care after ABI.

Psychologists involved in NR services will have to collaborate with important community leaders such as respected elders, religious clerics and traditional healers to improve accessibility of support and services. ${ }^{9}$ Places of worship, Non Governmental Organisations, and social welfare agencies are examples of existing infrastructure that can be used for interventions. Neuropsychologists need to collaborate with existing leaders like traditional healers and religious clerics to improve the accessibility to NR of those with $\mathrm{ABI} .^{25}$

\section{CONCLUSIONS}

NR services should emphasise a human rights focus, as enshrined in the Constitution of South Africa, ${ }^{26}$ to ensure an increase in accessibility of mental health services. This analysis examined some of the more significant dynamics within the South African context; however, its limitations include that it is not exhaustive, and it is also not universally applicable for all South Africans. The limitation of acknowledging that patients are often discharged to underprepared communities is that it does not challenge the reality that some patients do need more specialised care and that many families are involved in struggling to survive that and do not have the resources to devote to caregiving. Furthermore, healthcare professionals in the public sector are often overworked so may not have the time for the devolution of specialist skills.

A lack of accessibility to healthcare services in LMICs like South Africa results in the chronic and intricate sequelae of conditions such as ABI not receiving adequate levels of intervention, particularly in the postacute phase where patients need to reintegrate back into their community. Systems thinking and inclusive models of healthcare are needed in these circumstances where resource constraints necessitate creative and ecological forms of healthcare intervention.

Acknowledgements The author would like to make special mention of the contributions and guidance of Dr Edwine Barasa in the preparation of the article.

Funding This publication was funded by Alliance for Health Policy and Systems Research, an international partnership hosted by the WHO, with support from the Norwegian Government Agency for Development Cooperation (Norad), the Swedish International Development Cooperation Agency (Sida) and the UK Department for International Development.

\section{Competing interests None declared.}

Patient consent for publication Not required.

Provenance and peer review Not commissioned; externally peer reviewed.

Data availability statement No additional data are available.

Open access This is an open access article distributed in accordance with the Creative Commons Attribution Non Commercial (CC BY-NC 4.0) license, which permits others to distribute, remix, adapt, build upon this work non-commercially, and license their derivative works on different terms, provided the original work is properly cited, appropriate credit is given, any changes made indicated, and the use is non-commercial. See: http://creativecommons.org/licenses/by-nc/4.0/.

\section{ORCID iD}

Noorjehan Joosub http://orcid.org/0000-0003-4513-3942

\section{REFERENCES}

1. Laatsch L, Harrington D, Hotz G, et al. An evidence-based review of cognitive and behavioral rehabilitation treatment studies in children with acquired brain injury. J Head Trauma Rehabil 2007;22:248-56.

2. Wilson BA, Gracey F, Evans JJ, et al. Neuropsychological rehabilitation: theory, models, therapy and outcome. Neuropsychological rehabilitation: theory, models. Therapy 2009.

3. Alderman N, Knight C, Brooks J. Rehabilitation approaches to the management of aggressive behaviour disorders after acquired brain injury. Brain Impairment 2013:14:5-20.

4. World Health Organization. Towards a common language for functioning, disability and health ICF. Int Classif 2002;1149:1-22.

5. Gracey F, Evans JJ, Malley D. Capturing process and outcome in complex rehabilitation interventions: A "Y-shaped" model. Neuropsychol Rehabil 2009;19:867-90.

6. McDonald S, Tate R, Togher L, et al. Social skills treatment for people with severe, chronic acquired brain injuries: a multicenter trial. Arch Phys Med Rehabil 2008.

7. Parsonage M. Report an economic analysis traumatic brain injury and offending. Cent Ment Heal 2016.

8. Mahomed A. Rehabilitation of executive functioning following pediatric traumatic brain injury: evaluating a goal Management training intervention. Faculty of the Humanities 2015.

9. Pillay AL, Ahmed R, Bawa U. Clinical psychology training in South Africa: a call to action. South African Journal of Psychology 2013;43:46-58

10. Naidoo D. Traumatic brain injury: the South African landscape. S Afr Med J 2013;103:613-4.

11. Long W. On the Africanization of psychology. South African Journal of Psychology 2016;46:429-31.

12. Soeker MS, Van Rensburg V, Travill A. Are rehabilitation programmes enabling clients to return to work? return to work perspectives of individuals with mild to moderate brain injury in South Africa. Work 2012;43:171-82.

13. Chappell $P$, Johannsmeier $C$. The impact of community based rehabilitation as implemented by community rehabilitation facilitators on people with disabilities, their families and communities within South Africa. Disabil Rehabil 2009;31:7-13.

14. Cooper S, Nicholas L. An overview of South African psychology. Int J Psychol 2012;47:89-101.

15. Mbakile-Mahlanza L, Manderson L, Ponsford J. The experience of traumatic brain injury in Botswana. Neuropsychol Rehabil 2015;25:936-58.

16. Mokhosi MT, Grieve KW. African families' perceptions of traumatic brain injury. South African Journal of Psychology 2004;34:301-17. 
17. Coetzer R, Balchin R. Working with brain injury: a primer for PSYCHOLOGISTS working in under-resourced settings. A Primer for Psychologists Working in Under-Resourced Settings, 2014.

18. Alexander. et al.pdf.

19. Webster J, Taylor A, Balchin R. Traumatic brain injury, the hidden pandemic: a focused response to family and patient experiences and needs. S Afr Med J 2015;105:195-8.

20. Nell V. Cross-cultural neuropsychological assessment : theory and practice. Lawrence Erlbuam Associates, Publishers, 2000: 289

21. Stols A, Roos V, Hoffman J. Middle Adolescents' Motivations to Care for Older Persons in an Economically Vulnerable Community. $J$ Intergener Relatsh 2016;14:179-96.

22. Adam T, Hsu J, de Savigny D, et al. Evaluating health systems strengthening interventions in low-income and middle-income countries: are we asking the right questions? Health Policy Plan 2012;27(suppl 4):iv9-19.
23. Swanson RC, Cattaneo A, Bradley E, et al. Rethinking health systems strengthening: key systems thinking tools and strategies for transformational change. Health Policy Plan 2012;27(suppl 4):iv54-61.

24. Willis $C D$, Riley BL, Best $A$, et al. Strengthening health systems through networks: the need for measurement and feedback. Health Policy Plan 2012;27(suppl 4):iv62-6.

25. Ferreira J. South Africa GDP Growth Rate | 2018 | Data | Chart | Calendar | Forecast [Internet], 2016. Available: https:// tradingeconomics.com/south-africa/gdp-growth [Accessed $24 \mathrm{Nov}$ 2018]

26. Parliament of the Republic of South Africa. The constitution of the Republic of South Africa, act 108 of 1996. Constututional laws, 2005. 